\title{
Vertical profiling of convective dust plumes in southern Morocco during SAMUM
}

\author{
By ALBERT ANSMANN ${ }^{1 *}$, MATTHIAS TESCHE ${ }^{1}$, PETER KNIPPERTZ ${ }^{2}$, EIKE BIERW IRTH ${ }^{2}$, \\ DIETRICH ALTHAUSEN ${ }^{1}$, DETLEF MÜLLER ${ }^{1}$ and OLIVER SCHULZ ${ }^{3}, \quad{ }^{1}$ Leibniz Institute for \\ Tropospheric Research, Permoserstr. 15, 04318 Leipzig, Germany; ${ }^{2}$ Institute for Atmospheric Physics, Johannes \\ Gutenberg University, Becherweg 21, 55099 Mainz, Germany; ${ }^{3}$ Department of Geography, University of Bonn, \\ Meckenheimer Allee 166, 53115 Bonn, Germany
}

(Manuscript received 31 December 2007; in final form 11 July 2008)

\begin{abstract}
Lifting of dust particles by dust devils and convective plumes may significantly contribute to the global mineral dust budget. During the Saharan Mineral Dust Experiment (SAMUM) in May-June 2006 vertical profiling of dusty plumes was performed for the first time. Polarization lidar observations taken at Ouarzazate $\left(30.9^{\circ} \mathrm{N}, 6.9^{\circ} \mathrm{W}, 1133 \mathrm{~m}\right.$ height above sea level) are analyzed. Two cases with typical and vigorous formation of convective plumes and statistical results of $5 \mathrm{~d}$ are discussed. The majority of observed convective plumes have diameters on order of 100-400 m. Most of the plumes (typically $50-95 \%$ ) show top heights $<1 \mathrm{~km}$ or $0.3 \mathrm{DLH}$ with the Saharan dust layer height DLH of typically 3-4 km. Height-to-diameter ratio is mostly 2-10. Maximum plume top height ranges from 1.1 to $2.9 \mathrm{~km}$ on the $5 \mathrm{~d}$. $5-26$ isolated plumes and clusters of plumes per hour were detected. A low dust optical depth $(<0.3)$ favours plume evolution. Observed surface, 1 and 2-m air temperatures indicate that a difference of 17-20 K between surface and 2-m air temperature and of $0.9-1 \mathrm{~K}$ between the 1 and 2-m temperatures are required before convective plumes develop. Favourable horizontal wind speeds are $2-7 \mathrm{~m} \mathrm{~s}^{-1}$.
\end{abstract}

\section{Introduction}

In strongly convective conditions with light winds the atmospheric boundary layer is characterized by vigorous thermals and downdrafts (Hess and Spillane, 1990). Rotating thermals, made visible by tracers of dust and debris, are frequently observed in these conditions (e.g. Sinclair, 1964, 1969; Carroll and Ryan, 1970; Ryan and Carroll, 1970; Ryan, 1972; Hess and Spillane, 1990; Snow and McClelland, 1990; Renno et al., 2004; Oke et al., 2007a). Dust lifting occurs in connection with dust devils, convective plumes, and regional to large-scale weather systems (Koch and Renno, 2005). Recently, Knippertz et al. (2007) and Engelstaedter and Washington (2007) discuss the potential of thunderstorm-induced density currents and surface wind gustiness to mobilize large amounts of dust particles. For an adequate description of the dust cycle in global circulation models the relative importance of the different dust lifting processes and the large spatial and temporal variability of each must be known. Most dust models, however, consider dust lifting by large-scale processes only.

\footnotetext{
*Corresponding author. e-mail: albert@tropos.de DOI: $10.1111 /$ j.1600-0889.2008.00384.x
}

Dust devils are defined as dusty convective vortices with typical diameters of less than $20 \mathrm{~m}$ and lifetimes of only a few minutes (Sinclair, 1969; Carroll and Ryan, 1970; Snow and McClelland, 1990; Balme and Greeley, 2006). Convective plumes (dusty plumes) are non-rotating updrafts, have diameters of about $100 \mathrm{~m}$, and can persist for about $1 \mathrm{~h}$, the time scale of boundary layer convection (Kaimal and Businger, 1970; Renno and Ingersoll, 1996; Koch and Renno, 2005). Exceptionally large dust devils with diameters of $100 \mathrm{~m}$ have also been observed (Snow and McClelland, 1990; Bluestein et al., 2004). Near-surface dusty plumes may sometimes trigger dust devil formation and the dust plumes and devils may merge at greater height to form large thermals that may reach the top of the boundary layer (Hess et al., 1988; Hunt et al., 1988; Hess and Spillane, 1990).

Dust devils and dusty plumes form under sunny conditions during clear to fair weather when extremely hot air near the surface rises quickly. High superadiabatic temperature gradients of $0.25-0.4^{\circ} \mathrm{C} \mathrm{m}^{-1}$ in the $0.3-10 \mathrm{~m}$ height layer (Ryan, 1972) or of $>0.9^{\circ} \mathrm{C} \mathrm{m}^{-1}$ in the $0.15-2.5 \mathrm{~m}$ height layer (Oke et al., 2007a) associated with soil surface temperatures of up to about $60^{\circ} \mathrm{C}$ favour their formation. Light winds with speeds from 1.5 to $7 \mathrm{~m} \mathrm{~s}^{-1}$ are required to allow dust devils and convective plumes to develop (Oke et al., 2007a). However, horizontal wind speeds 
in the generated vortices and plumes easily exceed 7-10 $\mathrm{m} \mathrm{s}^{-1}$ and are thus high enough to initiate the saltation-sandblasting process (Marticorena and Bergametti, 1995; Alfaro et al., 1997; Shao, 2001) by which silt-sized and sand particles as well as small dust particles are entrained into the air. Thus, dust devils and convective plumes provide a complementary mechanism to lift desert particles into the air at comparably low mean wind speeds $\left(<7 \mathrm{~m} \mathrm{~s}^{-1}\right)$.

During the Martian ATmospheric And Dust in the Optical and Radio (MATADOR) 2002 field campaign, Renno et al. (2004) found that the heat and dust fluxes in terrestrial convective plumes and dust devils can be many orders of magnitude larger than their background values of a few $100 \mathrm{~W} \mathrm{~m}^{-2}$ and a few $100 \mu \mathrm{g}\left(\mathrm{m}^{2} \mathrm{~s}\right)^{-1}$. Using typical vertical velocities in convective plumes and vortices of about 1 and $7 \mathrm{~m} \mathrm{~s}^{-1}$, respectively (Kaimal and Businger, 1970; Renno et al., 2004), Koch and Renno (2005) conclude that the average dust flux in dusty plumes is about 100 and $700 \mathrm{mg}\left(\mathrm{m}^{2} \mathrm{~s}\right)^{-1}$ in dust devils and that a typical convective plume can pump nearly $3000 \mathrm{~kg}$ of dust into the atmosphere during its lifetime, a typical dust devil about $20 \mathrm{~kg}$, and large dust devil of about $100 \mathrm{~m}$ diameter can inject nearly $15000 \mathrm{~kg}$ of dust into the atmosphere.

Koch and Renno (2005) show that small-scale processes may be an important component of the global budget of mineral dust. They estimate that dust devils and convective plumes contribute to about $35 \pm 19 \%$ (dust devils $26 \pm 18 \%$, convective plumes $8 \pm 6 \%$ ) of the global mineral dust budget, and up to $13 \%$ of the total particulate emission. However, these values are mainly based on assumptions rather than observations. It is, for example, assumed that the frequency of occurrence of dust devils is much larger than the occurrence of convective plumes. Measurements that corroborate this assumption are not available. Vertical dust fluxes have also never been measured neither in dust devils nor in dusty plumes. Relatively little is known from direct field observations about the nature of sediment being entrained (Oke et al., 2007b). From studies of Gillette and Sinclair (1990) and Oke et al. (2007b) one may conclude that mainly silt-sized particles with diameters from 5 to $60 \mu \mathrm{m}$ are injected into the lower atmosphere. The majority of these particles falls out rapidly and is removed from the atmosphere within a few kilometres of range. It needs to be investigated, how large the fraction of lifted small submicron dust particles is that can be transported over several hundreds or even thousands of kilometres and may contribute significantly to the regional to continental dust load and may even be transported to other continents (Mattsson et al., 1993; Ansmann et al., 2003). The height that the dust particles can reach by lifting in the plumes and vortices is widely unknown. Measurements of typical heights of dust devils and convective plumes are not available. Thus, more observations are required before a trustworthy evaluation of the role of dust devils and convective plumes in the climate system is possible.

Bell (1969) and Hess and Spillane (1990) present the only studies on the occurrence of convective plumes with special em- phasis on the vertical extension of the plumes. However, these studies are based on by-eye-observations and they only provide information on the top height of the highest plume (maximum top height) of the observed plume ensembles. Plume height statistics is not reported. Bell (1969) conducted a survey of general aviation pilots in western Queensland, Australia. Replies to his questionnaire indicate that during the summer it is common for general aviation pilots to see multiple dust devils and convective plumes (between 5 and 100) at one time. Maximum top heights were between 1200 and $2400 \mathrm{~m}$. Hess and Spillane (1990) evaluated a survey of pilots, air traffic controllers, and meteorologists in Australia from November 1987 to January 1988. In strongly convective conditions there were two preferred heights attained by the dust, one at about $0.1 h$ (with the boundary layer height $h$ ) and the other at about $0.5 \mathrm{~h}$. The boundary layer reaches heights of typically $>3 \mathrm{~km}$ in summer over desert areas. Dust devils were estimated to be at least five times higher than they are wide. The ratio of the (visible) maximum top height of observed plume and dust devil ensemble to the (visible) maximum diameter of the largest plume in the ensemble was found to range on average from 20 to 25 . 18 cases were analysed.

The highest part of the plume is however hard to be detected by eye. As described by Ryan and Carroll (1970) (and firstly defined by Sinclair in his $\mathrm{PhD}$ thesis) the highest part of the dust devil begins where the upper part of the visible vortex becomes turbulent, with the dust (if still visible) diffusing radially with height in a manner analogous to a detraining jet or plume. The finest fractions of dust are found in these upper regions. The diluted plumes may horizontally cover an area of several hundreds of metres at these heights. This circumstance makes it impossible to properly estimate the top of a convective plume by eye.

Dust-sensitive instruments like lidars are required to provide more insight into the vertical structure of dust devils and dusty plumes. A lidar easily detects the weakest traces of dust. A polarization lidar (explained in Section 2) is especially useful because the measured depolarization ratio is highly sensitive to the size of the particles and increases with particle size. The typical dust depolarization ratio is about 30-35\% (Ansmann et al., 2008; Freudenthaler et al., 2008). The values can exceed $40 \%$ in dust plumes. As mentioned, dust devils and convective plumes contain a significant fraction of large silt-sized particles with diameters from 2 to $60 \mu \mathrm{m}$ (Greeley et al., 2003; Oke et al., 2007b) and can thus be easily contrasted from the background dust (with particle diameters mostly $<2 \mu \mathrm{m}$ ). Furthermore, continuous lidar monitoring provides an integrated view of atmospheric motions from larger-scale boundary-layer up and downdrafts to the small-scale plumes and devils.

In this contribution, we present, to the best of our knowledge, for the first time lidar observations of height profiles of dust plumes. The observations were conducted in the framework of the Saharan Mineral Dust Experiment (SAMUM, Heintzenberg, 2008) in southern Morocco in May-June 2006. After a short 
description of the field site and the used lidar technique in Section 2, Section 3 presents the lidar observations. Section 4 provides a discussion of the findings in the context of the general dust and meteorological conditions (with focus on surface, and 1 and 2-m air temperatures). A short summary is given in Section 5.

\section{Experiment}

\subsection{Field site}

The Airport of Ouarzazate $\left(30.9^{\circ} \mathrm{N}, 6.9^{\circ} \mathrm{W}, 1133 \mathrm{~m}\right.$ height above sea level, a.s.l.) is located in a flat basin bounded by two almost parallel steep mountain chains of the High Atlas (more than $4000 \mathrm{~m}$ high) and the Anti-Atlas/Jebel Saghro (up to $2700 \mathrm{~m}$ high). The east-west and north-south extension of the basin is about 60-80 and 30-50 km, respectively. The region experiences substantial solar heating in May and June. The almost tree-free steppe vegetation consists of mainly small bushes having a low height and cover less than $20 \%$ of the surface.

The climate of the region is semi-arid. Rainfall occurs in short intense episodes sometimes resulting in more than $10 \mathrm{~mm}$ of precipitation within $1 \mathrm{~h}$. Ouarzazate received about 80 and $9 \mathrm{~mm}$ rain in the 6 and 3 months preceding the SAMUM campaign, respectively. The last rain of $1 \mathrm{~mm}$ before SAMUM fell on 24 April 2006 and thus about 3 weeks before the lidar observations began. Thus, soil moisture is usually low so that solar heating leads to a large Bowen ratio (ratio of sensible to latent heat flux, Stull, 1988). However, on May 26 and 27 thunderstorms developed and caused precipitation of 7 and $15 \mathrm{~mm}$, respectively, and flooding of several streets in Ouarzazate.

The city centre of Ouarzazate (40000 inhabitants) is located a few kilometres south of the airport. The airflow from southeast to southwest and thus the development of dust plumes in this air mass may be affected by nearby buildings. The cases discussed in detail in Section 3 were sampled during easterly and westerly wind situations. Furthermore, the Mansour Eddahbi Water Reservoir (several kilometres north-south extension, about $15 \mathrm{~km}$ east-west extension) is situated a few kilometres to the east of Ouarzazate and may have some influence on the development of dust devils and plumes.

\subsection{Lidar}

Three lidars were deployed at the Ouarzazate airport during SAMUM (Tesche et al., 2008). In this study we use the six-wavelength aerosol lidar Backscatter Extinction lidar-Ratio Temperature Humidity profiling Apparatus (BERTHA) of the Leibniz Institute for Tropospheric Research (Althausen et al., 2000; Tesche et al., 2008). BERTHA transmits six wavelengths from 355 to $1064 \mathrm{~nm}$. Linearly polarized laser light is emitted. At $710 \mathrm{~nm}$, the cross- and parallel-polarized signals (with respect to the laser-light polarization) are detected separately. The incomplete overlap of the laser beam with the receiver field-of- view prohibit the detection of pronounced convective plumes at heights below $300 \mathrm{~m}$ above the lidar.

Dust devil observations are based on the 710-nm signals. To properly resolve plumes with diameters of about 100-500 m at heights above $300 \mathrm{~m}$ the lidar signal profiles were stored with 10-s resolution. Laser-beam-pointing to the west at a fixed off-zenith angle of $45^{\circ}$ during most of the morning lidar sessions was chosen to avoid a strong influence of Sun light on the measurements that usually took place between 1000 and 1330 UTC (UTC = Local Time, LT). On May 16, the zenith angles were $5^{\circ}-30^{\circ}$. The May- 16 observation is discussed in detail in Section 3.

The depolarization ratio, simply given by the (calibrated) ratio of the cross-polarized to the parallel-polarized 710-nm backscatter signal, permits us to discriminate, for example, cloud layers of liquid drops from layers with predominating ice crystal backscattering (Ansmann et al., 2008), and, as used here, to identify dust plumes containing many dust and sand particles. Dust particles (with typical diameters $<10 \mu \mathrm{m}$ ) cause a depolarization ratio of around 30\% at $710 \mathrm{~nm}$ (Ansmann et al., 2008; Freudenthaler et al., 2008). Large dust particles and sand particles cause large depolarization (depolarization ratio of $50-100 \%$ ) as our observations indicate.

It is worth noting that depolarization observations at a comparably long laser wavelength as 710 or $1064 \mathrm{~nm}$ are of advantage compared to studies at the two frequently used short laser wavelengths of 355 or $532 \mathrm{~nm}$. The impact of Rayleigh scattering, causing a depolarization ratio of $2 \%$ or less, is a factor of 16 and 8 smaller at $710 \mathrm{~nm}$ than at 355 and $532 \mathrm{~nm}$, respectively. The dust-to-Rayleigh backscatter ratio is $2-7$ at $710 \mathrm{~nm}$ for typical dust conditions and $0.1-0.4$ at $355 \mathrm{~nm}$. Thus the total (Rayleigh + dust particle) depolarization ratio at $710 \mathrm{~nm}$ is widely determined by dust, and almost not influenced by Rayleigh scattering. An increase of the total 710-nm depolarization ratio, say from 30 to $50 \%$ or to even higher values, is clearly linked to the size of the non-spherical particles, and almost not dependent on the change in the relative dust load. The opposite is the case at $355 \mathrm{~nm}$.

\subsection{Thermal broad-band spectrometer and Sun photometry}

A downward looking pyrgeometer (thermal broad-band spectrometer) was mounted at $1.5 \mathrm{~m}$ above ground and measured the upwelling broadband thermal radiation in the spectral range from 4 to $42 \mu \mathrm{m}$ over the surface. The pyrgeometer is a CG-4 type manufactured by Kipp \& Zonen (Delft, The Netherlands). The ground was not bituminized and represents the soil characteristics in the near surroundings and in the Ouarzazate basin very well. Unfortunately, the measurements only cover the period from 19 May to 4 June, but not the two periods with maximum dust plume activity from May 16 to 18 and from June 5 to 7 . 
We estimate the surface temperature from the measured thermal broadband radiation by applying the Stefan-Boltzmann law. The law describes the radiant energy emitted by a unit area of surface of a blackbody radiator according to $Q_{\mathrm{B}}=\sigma T^{4}$ where $Q_{\mathrm{B}}$ is the emitted flux density ( $\mathrm{W} \mathrm{m}^{-2}$ ), $\sigma$ is the Stefan-Boltzmann constant $\left(5.67 \times 10^{-8} \mathrm{~W} \mathrm{~m}^{-2} \mathrm{~K}^{-4}\right)$, and $\mathrm{T}$ is the temperature in Kelvin. In case of grey surfaces (like desert and steppe soils) with an emissivity of $\eta=0.9-1$, the emitted energy is $Q_{\mathrm{G}}=\eta \sigma T^{4}$.

The uncertainty of the spectrometer is $7.5 \mathrm{~W} \mathrm{~m}^{-2}$, which corresponds to an error in the estimated temperature of about $1 \mathrm{~K}$. By comparing the temperatures derived from the broadband radiation with direct measurements (a PT100 element put on the ground), we conclude that the emissivity of the surface soil material is close to 0.97 . Here, we assume that the PT100 (in contact with the soil as well as with the cooler air) measures a temperature that is lower by $1-2 \mathrm{~K}$ than the soil surface temperature. Keeping all error sources in mind the surface temperatures presented in Section 4 have an uncertainty of about $2.5 \mathrm{~K}$. We further checked the reliability of the surface temperature estimation by comparing the Ouarzazate values with surface temperatures extrapolated from ground temperature observation at Trab Labied $40 \mathrm{~km}$ northeast of Ouarzazate (see next subsection). Good agreement was found.

An Aerosol Robotic Network (AERONET) station was run during SAMUM (see AERONET web page, Holben et al., 1998). The AERONET Sun photometer measures the particle optical depth from 340 to $1640 \mathrm{~nm}$. The uncertainty in the optical depth values is less than $0.01-0.02$ at wavelengths $<500 \mathrm{~nm}$ and less than 0.01 for the larger wavelengths.

\subsection{Meteorological data}

Every morning, mostly around 1030 UTC, a Vaisala radiosonde was launched. The radiosonde (type RS92) measured height profiles of air pressure, temperature, relative humidity, horizontal wind speed and direction up to $15-20 \mathrm{~km}$ height. The uncertainties in the Vaisala sonde data are about $1.5 \mathrm{hPa}, 0.5 \mathrm{~K}, 5 \%$, and $0.5 \mathrm{~m} \mathrm{~s}^{-1}$ (van As et al., 2006).

At the airport, the World Meteorological Organization runs a weather station (WMO site no. 60265). This station records meteorological parameters such as air temperature, pressure, humidity at $2 \mathrm{~m}$, and wind velocity and direction at $10 \mathrm{~m}$ height above ground. The station is about $500 \mathrm{~m}$ to the west of the lidar site.

In the framework of the IMPETUS (Integratives Management-Projekt für einen Effizienten und Tragfähigen Umgang mit Süßwasser in Westafrika) project (Speth and Diekkrüger, 2006), 13 meteorological surface stations are run in the Drâa catchment in southeastern Morocco ranging from the southern slopes of the High Atlas Mountains to its xeric foreland (Schulz, 2006; Knippertz et al., 2007). The IMPETUS station Trab Labied $\left(31.2^{\circ} \mathrm{N}, 6.6^{\circ} \mathrm{W}, 1383 \mathrm{~m}\right.$ a.s.1.) is located about $40 \mathrm{~km}$ northeast of Ouarzazate. The landscape and vegetation is similar to the one at Ouarzazate. Besides other parameters air temperature at 1- and 2-m height above ground level (a.g.l.), and soil temperatures at 5,15 and $30 \mathrm{~cm}$ below the surface are recorded. Measurements are taken every $5 \mathrm{~min}$ and the respective 15-min averages are stored.

From the different soil temperatures, the surface temperature is estimated and compared to the one retrieved from the spectrometer observations at Ouarzazate. The diurnal amplitudes of the temperature curves at the different depths of 5, 15 and $30 \mathrm{~cm}$ show an exponential decrease with depth and also an increasing phase lag with respect to the diurnal cycle of solar radiation. From this behaviour, the diurnal cycle of the surface temperature is estimated after Monteith (1973). This temperature retrieval works well. For example, on May 19, 2006, the maximum surface temperature measured at Ouarzazate was $56^{\circ} \mathrm{C}$. At Trab Labied we estimated a maximum surface temperature of $54-55^{\circ} \mathrm{C}$, about $7.5-8^{\circ} \mathrm{C}$ higher than the $5-\mathrm{cm}$ soil temperature. The air temperature at $2 \mathrm{~m}$ height a.g.l. was also about $2^{\circ} \mathrm{C}$ lower than at Ouarzazate. This can be explained by a difference of $250 \mathrm{~m}$ in elevation and a dry-adiabatic lapse rate.

\section{Lidar observations of convective plumes}

\subsection{Case study of 16 May 2006}

Optimum conditions for the formation of dust plumes and vortices were given from May 16 to 18. The absence of clouds, weak easterly winds, and a comparably low particle optical depth of $0.2-0.3$ at $500 \mathrm{~nm}$ of the 3-4-km thick Saharan dust layer guaranteed strong heating of the ground and the development of favourable super adiabatic lapse rates. The Saharan air mass was advected from central-southern Algeria to the field site within $3 \mathrm{~d}$ according to backward trajectories.

A short section of the lidar observation is shown in Fig. 1. The entire measurement period of more than $2 \mathrm{~h}$ is given in Fig. 2 together with radiosonde information on temperature, humidity, and wind conditions. The lidar data in the figures are corrected for overlap effects (laser beam with receiver field of view) in the near range. However, the values in the lowermost $500 \mathrm{~m}$ have to be handled with caution. Residual uncertainties in the overlap correction are too large to allow a trustworthy interpretation of the lidar observations below this height. Thus, plumes can only be identified if they are higher than $300 \mathrm{~m}$.

The lidar signals in Fig. 1 in the upper panel (and in the following colour plots) are signal counts that are collected within each 10-s time interval and within each $15-\mathrm{m}$ height bin. These signals are, in addition, corrected for the decrease of the signal strength with $R^{2} . R$ denotes the distance of the backscatter region (air volume) from the lidar in metres. The multiplication of the signal counts with $R^{2}$ yields the shown large numbers. As an example, the backscatter signal strength is 12500 counts for the height of $4 \mathrm{~km}$ (see yellow signals in Fig. 1). After multiplication 
SAMUM, Ouarzazate $(30.9$ N, 6.9 W) , 16/05/06, 12:20 - 12:40 UTC

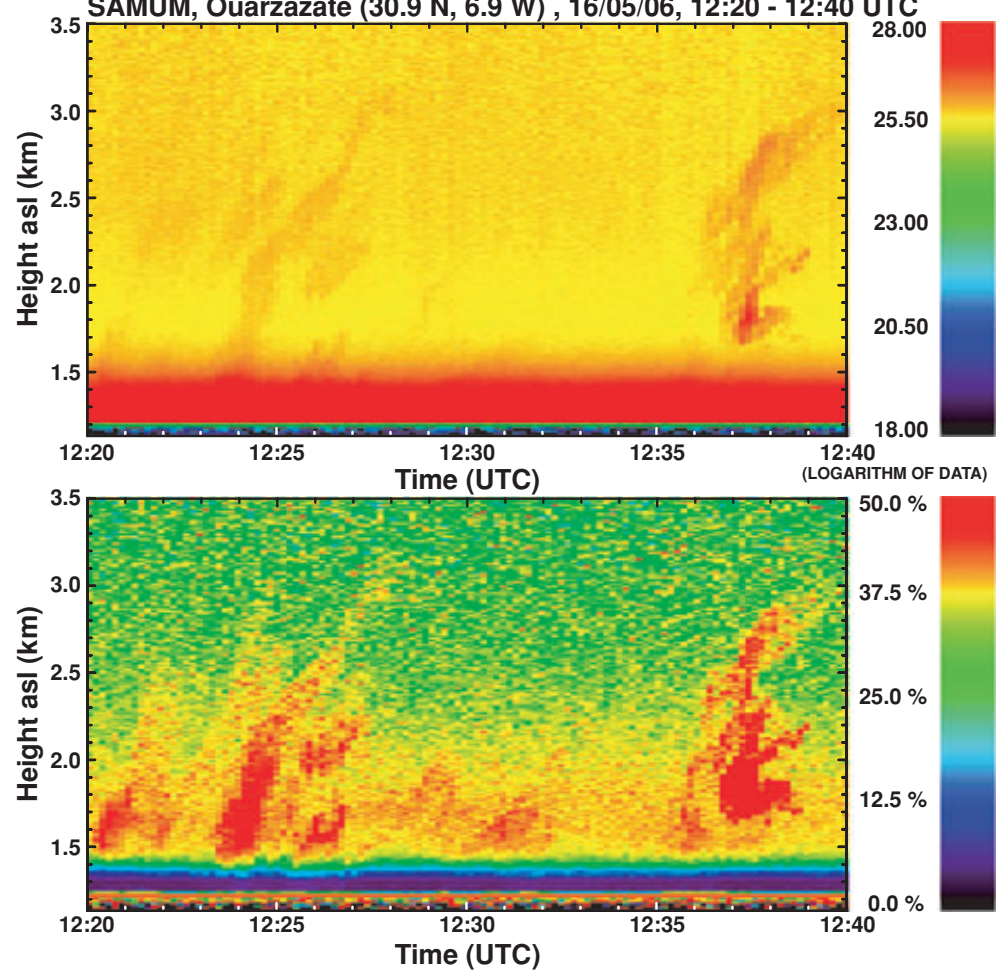

Fig. 1. Lidar observation of convective plumes on 16 May 2006, 1220-1240 UTC. The 710-nm range-corrected backscatter signal (top, arbitrary units) and the 710-nm total depolarization ratio (bottom panel, in percent) are shown. Observations are taken at a zenith angle of $30^{\circ}$ with a range resolution of $15 \mathrm{~m}$ and temporal resolution of $10 \mathrm{~s}$. with $R^{2}=16 \times 10^{6} \mathrm{~m}$ we obtain a number of $2 \times 10^{11}$ or 26 in logarithmic scale. This number is shown in Fig. 1.

Figure 1 highlights the period with the strongest convective activity observed on 16 May 2006. The figure almost shows the plumes as they would appear in reality (on a photo from the side). The vertical and horizontal axes correspond to the same length scale for a horizontal wind speed around $4 \mathrm{~m} \mathrm{~s}^{-1}$ as is the case on May 16. The tilt of the plumes to the right with height results from the fact that the plumes are advected from the east and the laser beam is pointing to the west (at a zenith angle of $30^{\circ}$ to that time) so that the lower part of a plume is detected first before the upper part of a plume crosses the laser beam at greater heights.

The height-time display of the range-corrected 710-nm signal in Fig. 1 indicates coherent filament-like structures up to heights of 1-2 km above ground. The dust plumes are better seen in the depolarization height-time display. The plumes contain significantly more large dust and sand particles than the dust background aerosol. The temporal width of the plumes in Fig. 1 is roughly $30-90$ s so that the diameters of the convective plumes are about $100-400 \mathrm{~m}$ at heights $>500 \mathrm{~m}$ above the lidar. In the estimation of the plume diameter, we consider a horizontal wind speed of $4 \mathrm{~m} \mathrm{~s}^{-1}$ (see Fig. 2). The complex plume observed after 1235 UTC may have formed from several smaller ones. The two large plume clusters (observed around 1225 and after 1235 UTC) reach heights of $2 \mathrm{~km}$ a.g.l. The height-to-diameter ratio is roughly $5-10$.
Figure 2 provides an overview of the entire measurement up to heights well above the Saharan dust layer. According to the radiosonde observation light winds blowing from the east prevail in the dust layer. The relative humidity increases from values around $20 \%$ at ground to about $80 \%$ in the upper part of the dust layer. The virtual potential temperature indicates a well-mixed boundary layer up to $3-3.5 \mathrm{~km}$ height a.s.1. around 1050 UTC. Slightly stable conditions are observed in the residual layer.

Strong updrafts (see arrows in Fig. 2) surrounded by downdraft areas mark the evolution of the convective boundary layer (CBL). The updrafts steadily increase with time from about $3 \mathrm{~km}$ height a.s.l. at $1050 \mathrm{UTC}$ to $5 \mathrm{~km}$ height a.s.1. $2 \mathrm{~h}$ later. The updrafts occur with a frequency of roughly 15-20 min. The oscillation of the dust layer top may have been partly caused by the periodic convective activity in the CBL. Note that the updrafts pump less dusty air into the upper part of the dust layer. The backscatter signals in the yellow updrafts (e.g. after $1050 \mathrm{UTC}$, at $4.5 \mathrm{~km}$ height) are smaller than the backscatter signals in the orange areas (before 1050 UTC, $4.5 \mathrm{~km}$ height) by almost a factor of 3 . The backscatter signal strength is proportional to the particle concentration. Only the convective plumes (red features in the depolarization plot) inject particles. Distinct convective plumes are not visible in the depolarization observations before 1045 UTC. Five clusters of plumes can be counted during the first hour of plume activity in Fig. 2. 


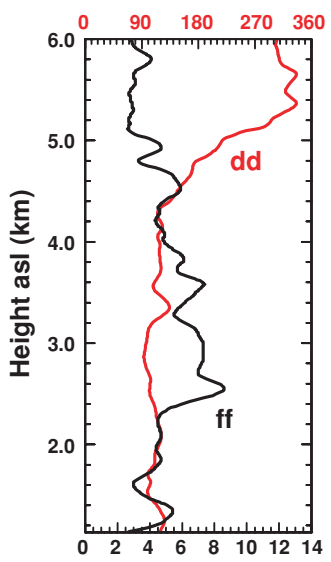

SAMUM, Ouarzazate (30.9 N, 6.9 W) , 16/05/06, 10:40 - 12:56 UTC
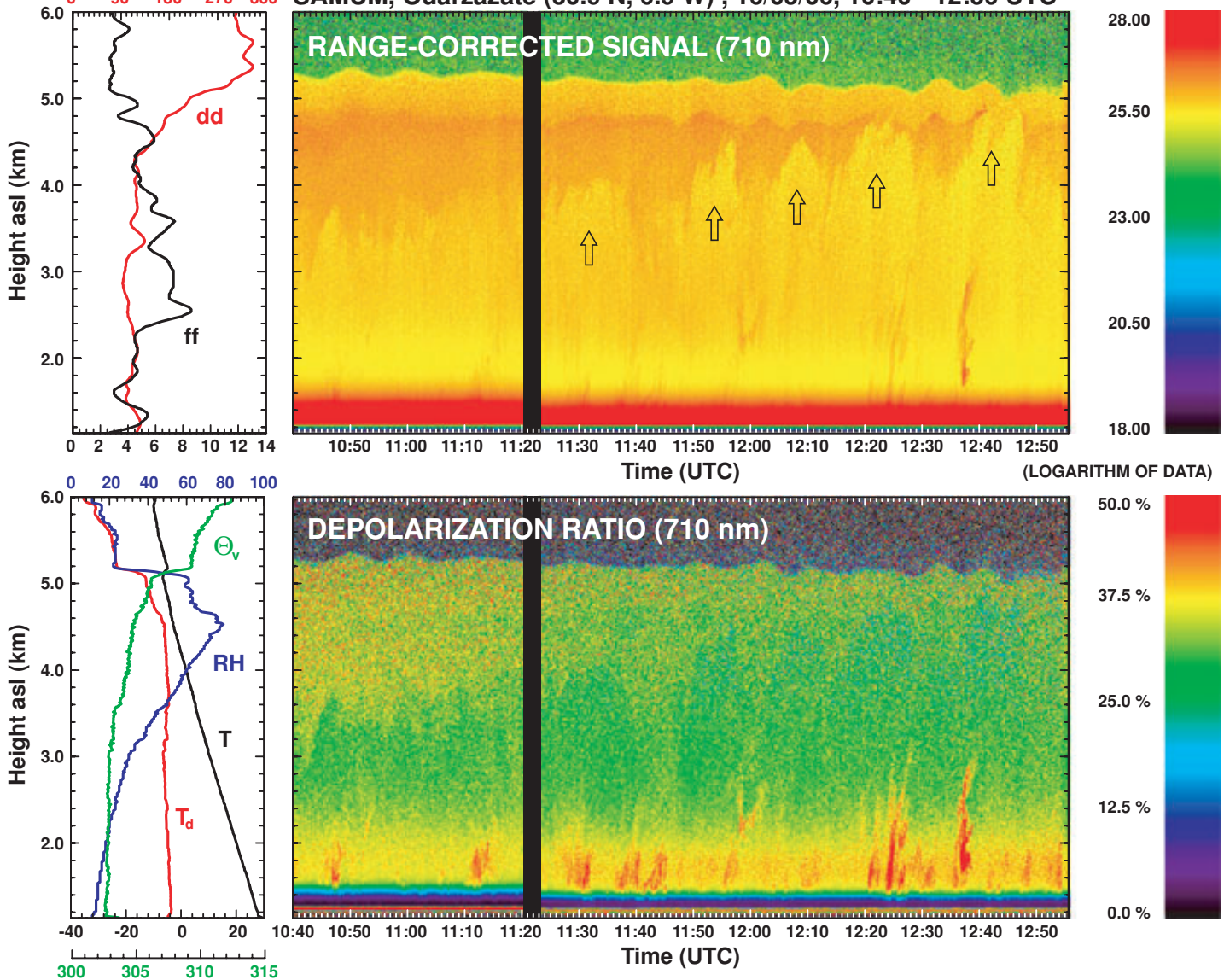

Time (UTC)

(LOGARITHM OF DATA)
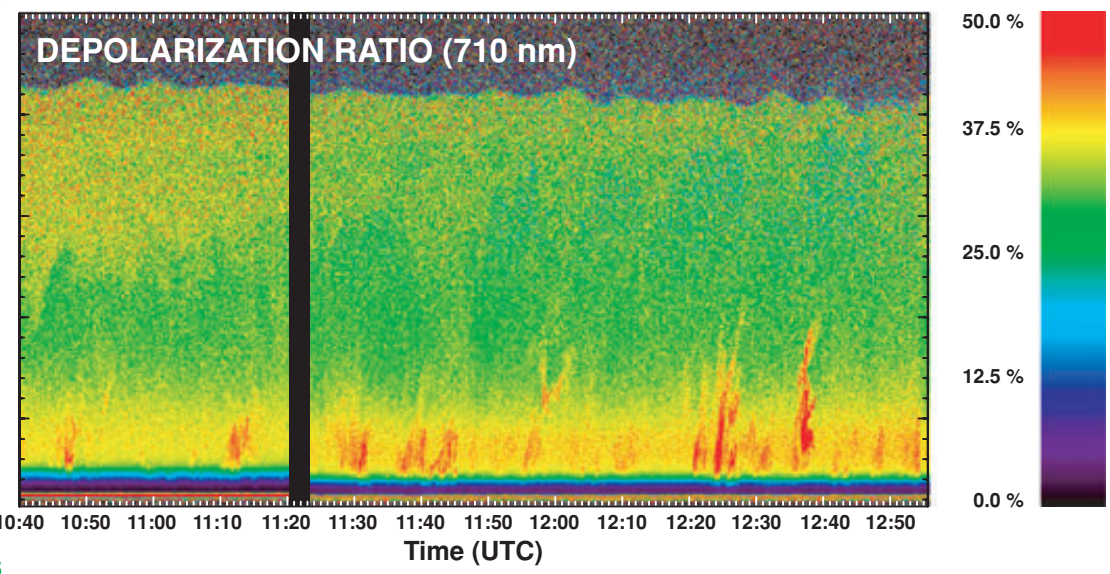

Fig. 2. Lidar observations of convective plumes (red in the depolarization plot) and updrafts (yellow in the signal plot, the last five updrafts are indicated by arrows) in the convective boundary layer developing within the 4-km-thick Saharan dust layer with oscillating top. The observation is taken on 16 May 2006, 1040-1256 UTC. Range-corrected 710-nm signal (top, arbitrary units) and respective depolarization ratio as a function of height and time are shown. Lidar observations are taken at a zenith angle of $5^{\circ}$ and $30^{\circ}$ until $1120 \mathrm{UTC}$ and after $1123 \mathrm{UTC}$, respectively. Left-hand side panels show radiosonde profiles of wind direction (dd) and wind velocity (ff, top panel), and relative humidity $R H$, temperature $T$, dew point $T_{\mathrm{d}}$, and virtual potential temperature $\theta_{\mathrm{v}}$ (bottom panel). The radiosonde was launched at 1040 UTC.

It is interesting to note that Hess and Spillane (1990) mentioned that the updraft-downdraft separation is typically about $0.75 h$ with boundary layer height $h$. From 1150 to 1250 UTC four updrafts are observed, the average updraft-downdraft separation is roughly $7.5 \mathrm{~min}$ or about $3000 \mathrm{~m}$ when taking into account a mean horizontal wind speed of $7 \mathrm{~m} \mathrm{~s}^{-1}$ at $3 \mathrm{~km}$ height a.s.l. Thus the updraft-downdraft distance is roughly $0.75 h$ in Fig. 2.

Dust devils do not appear to be isolated convective phenomena and instead form as part of the local convective system (Sinclair, 1969; Kaimal and Businger, 1970; Ryan and Carroll, 1970; Hess et al., 1988). The appearance of the convective plumes is partly in phase with the updraft-downdraft motion. The strength of the plumes expressed by their height is linked to the strength (or height) of the updrafts as suggested by Hess and Spillane (1990). With time the updrafts as well as the plumes reach increasingly greater heights. Carroll and Ryan (1970) noted a similar behaviour as shown in Fig. 2. They interpreted near-surface data to signify that the timescales of atmospheric convection govern dust devil activity. Sinclair (1969) suggests that periods of particularly intense dust devil activity 'stir up' the superadiabatic boundary layer to such an extent that it suppresses dust devil formation and requires some time to re-establish itself. Downdraft periods may favour the re-establishment of surface-near instable conditions (Hess and Spillane, 1990).

As mentioned, strong convection can lift a considerable amount of large dust particles and even sand particles into the air (Oke et al., 2007b). The increased values of the depolarization ratio (yellow to red in Fig. 2) in the lowermost 1000-1500 m above the lidar corroborate this. The steadily increasing amount of large particles enhances the background depolarization level significantly. The large particles fall out immediately after injection.

The strength (count rate) of the range-corrected backscatter signal and thus the particle concentration inside the strong plume cluster at 1237 UTC is a factor of 10 larger than the strength of the 

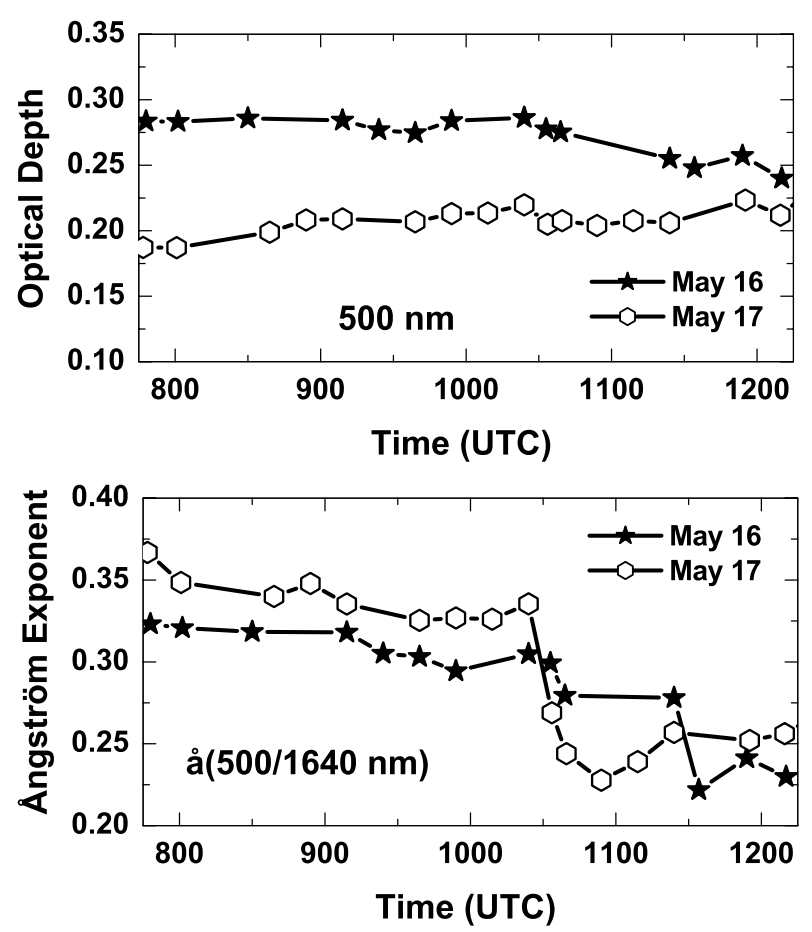

Fig. 3. Particle optical depth (AOD, $500 \mathrm{~nm}$ wavelength) and Ångström exponent (AE, computed from 500 and 1640-nm particle optical depths). Values are derived from AERONET Sun photometer observation on 16 and 17 May 2006.

backscatter signals outside the plume. Correspondingly, the light extinction coefficients estimated from the backscatter signals at $532 \mathrm{~nm}$ indicate an increase of the extinction coefficients from $50 \mathrm{Mm}^{-1}$ outside the plume to values around $500 \mathrm{Mm}^{-1}$ at $1.5 \mathrm{~km}$ height. Renno et al. (2004) reported horizontal scans at $100 \mathrm{~m}$ height with a ground-based lidar through dust devils. The lidar scans revealed a ratio the signal strengths inside and outside the dust devil of about of 1000, and thus a dust concentration (or extinction coefficient) difference of roughly a factor of three orders of magnitude. The difference is mainly caused by the fact that MATADOR took place in the desert (with a lot of fine particles that can be lifted), whereas our measurement was conducted in a steppe-like area, where less dust particles are available.

The AERONET Sun photometer observations in Fig. 3 corroborate that the mean size of the light-scattering particles increases after the onset of the dust plume period (after 1000 UTC). On May 16 and 17 a significant decrease of the Ångström exponent is observed after 1100 and 1000 UTC, respectively. The Ångström exponent (Ångström, 1961) is computed from the particle optical depths measured at 500 and $1640 \mathrm{~nm}$ and describes the wavelength dependence of light scattering in the respective spectral range. The lower the Angström exponent, the larger the particles. The Ångström exponent for the dust background is $0.3-0.35$ in Fig. 3. On May 16, the
Ångström exponent decreases from values around 0.3 to values below 0.25 not before 1130 UTC. Figure 2 shows that this behaviour coincides with the increased dust plume activity after 1100 UTC.

On May 17, the sudden decrease of the Ångström exponent occurs earlier and is more pronounced. The Sun photometer observed a particle optical depth around 0.21 at $500 \mathrm{~nm}$ and of 0.14 at $1640 \mathrm{~nm}$ and correspondingly an Ångström exponent of 0.34 at 1030 UTC. The sudden drop to 0.23 close to 1100 UTC reflects the increase of the $1640-\mathrm{nm}$ optical depth from 0.14 at 1030 UTC to 0.16 at 1100 UTC. The dust plumes increased the optical depth at the long wavelength by about $10-15 \%$ because of enhanced light scattering by the large dust particles and sand particles. The AERONET channel for the longest wavelength is most sensitive to changes in the size characteristics. The overall change in the optical depth, however, is weak in this steppe-like area and mainly depends on changes in the meso- to large-scale air mass flow.

Kahn et al. (2008) report aerosol optical depth maps retrieved from the satellite instrument Multi-angle Imaging SpectroRadiometer (MISR) for the SAMUM region on May 19, 2006. MISR views nearly the entire Earth about once per week, with spatial sampling of $275 \mathrm{~m}$ to $1.1 \mathrm{~km}$, depending on channel and instrument operating mode. On 19 May 2006, the MISR retrievals show a greater spatial variability of the aerosol optical depth in the vicinity of the SAMUM field site of Tinfou (close to the border to Algeria) than at Ouarzazate. Correspondingly, the temporal variability of the optical depth was higher at Tinfou. Occasional peaks are visible in the Tinfou Sun photometer times series. The increase in the aerosol optical depth is of the order of 0.05-0.1. Kahn et al. (2008) conclude that local dust sources may have been active during the late morning.

\subsection{Case study of 23 May 2006}

Figure 4 shows the observation on 23 May 2006, from 1024 to 1136 UTC. An exceptionally vigorous development of thermals (updrafts) and dust plumes is observed on this day. Every second minute a convective feature crosses the laser beam. Figure 5 presents the subsequent period with a more typical behaviour of dust plume formation. Distinct plumes are visible in the depolarization colour plot. The coherent structures in the depolarization plots in Figs. 4 and 5 up to $>3 \mathrm{~km}$ height a.s.l. clearly indicate that the plumes transport a considerable amount of dust, siltsized, and sand particles up to heights of more than $2 \mathrm{~km}$ above the lidar.

Most plume and plume cluster top heights range from 300 to $700 \mathrm{~m}$ a.g.1. Only one major plume is observed that reaches a height $>3.5 \mathrm{~km}$ a.s.1. in Fig. 5. The lower part of this large plume did not penetrate through the laser beam. Plume diameters are of the order of 100-360 m according to a mean horizontal wind speed of about $3 \mathrm{~m} \mathrm{~s}^{-1}$ and a temporal plume width of 30$120 \mathrm{~s}$. Height-to-diameter ratios are roughly 2-7. 


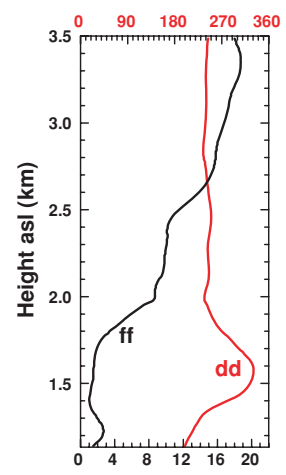

SAMUM, Ouarzazate $(30.9 \mathrm{~N}, 6.9 \mathrm{~W}), 23 / 05 / 06,10: 24$ - 11:36 UTC
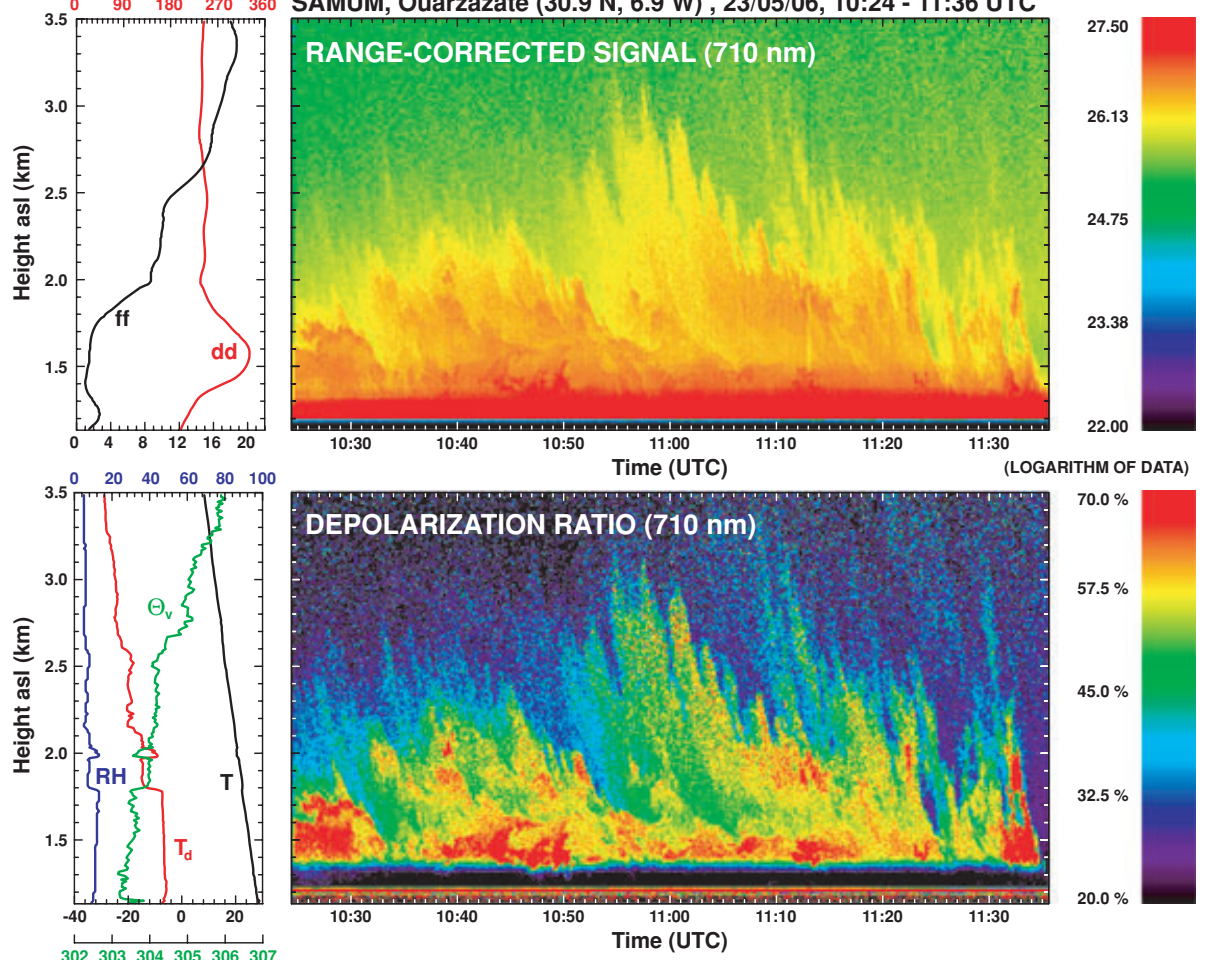

Fig. 4. Same as Fig. 2 except for 23 May 2006, 1024-1136 UTC. Meteorological parameters (left-hand side panels) were measured with a radiosonde launched at 1054 UTC. Exceptionally strong development of convective plumes is observed on this sunny day in an air mass characterized by a low relative humidity and a low dust optical depth of 0.025 .

Fig. 5. Same as Fig. 1, except for 23 May 2006, 1136-1218 UTC.

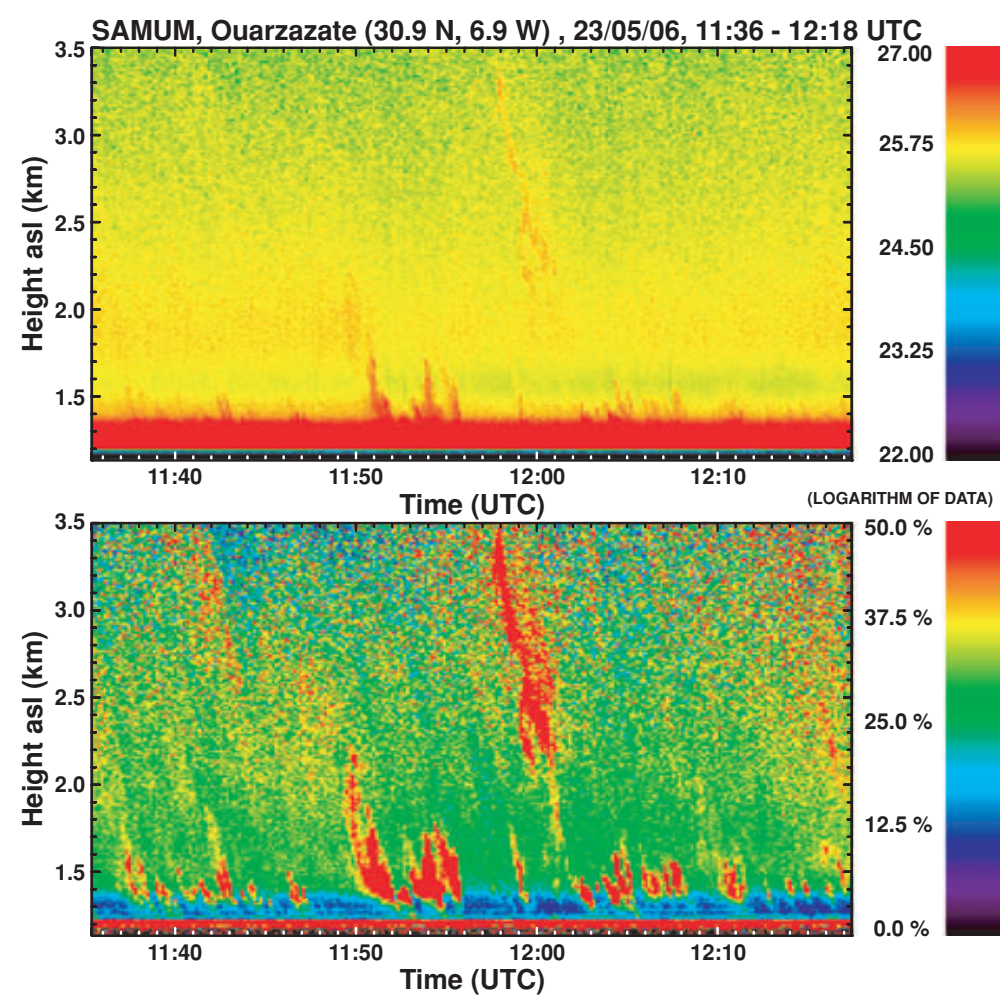


Table 1. Dust plume statistics for lidar observational periods (UTC = Local Time) on five different days: TNP $=$ total number of observed plumes, $\mathrm{FOP}=$ frequency of occurrence of dust plumes, $\mathrm{P} \mathrm{km}^{-2}=$ observed plumes per $\mathrm{km}^{2}$, PHM $=$ observed maximum plume top height above ground, and DLH = dust layer height above ground

\begin{tabular}{|c|c|c|c|c|c|c|c|c|c|c|c|}
\hline \multirow[t]{2}{*}{ Date } & \multirow{2}{*}{$\begin{array}{l}\text { Time } \\
\text { UTC }\end{array}$} & \multirow[t]{2}{*}{ TNP } & \multirow{2}{*}{$\begin{array}{l}\text { FOP } \\
\left(\mathrm{h}^{-1}\right)\end{array}$} & \multicolumn{5}{|c|}{ Plume top height frequency (\%) } & \multirow{2}{*}{$\begin{array}{l}\mathrm{P} \mathrm{km}^{-2} \\
\left(\mathrm{~km}^{-2}\right)\end{array}$} & \multirow{2}{*}{$\begin{array}{l}\text { PHM } \\
(\mathrm{km})\end{array}$} & \multirow{2}{*}{$\begin{array}{l}\text { DLH } \\
(\mathrm{km})\end{array}$} \\
\hline & & & & $0.3-0.5 \mathrm{~km}$ & $0.5-1 \mathrm{~km}$ & $1-1.5 \mathrm{~km}$ & $1.5-2 \mathrm{~km}$ & $>2 \mathrm{~km}$ & & & \\
\hline 14 May & $1105-1213$ & 11 & 9.7 & & 45 & 37 & 9 & 9 & 1.2 & 2.1 & 3.7 \\
\hline 16 May & $1040-1256$ & 12 & 5.3 & & 50 & 25 & 25 & & 1.0 & 2.0 & 4.0 \\
\hline 17 May & $1019-1218$ & 18 & 9.1 & 39 & 50 & 11 & & & 1.7 & 1.1 & 3.6 \\
\hline 18 May & $1054-1202$ & 12 & 10.6 & 42 & 17 & 33 & & 8 & 1.5 & 2.2 & 3.2 \\
\hline 23 May & $1136-1218$ & 18 & 25.7 & 62 & 33 & 5 & & 5 & 7.9 & 2.9 & \\
\hline
\end{tabular}

At detailed inspection of backward trajectories (not shown) and the radiosonde humidity (low relative humidity throughout the troposphere) and wind data revealed that the air mass over Ouarzazate in the morning of May 23 originated from the free troposphere over the Atlantic, from heights well above the maritime boundary layer. The atmosphere contained almost no dust in the morning hours according to the AERONET Sun photometer and the SAMUM lidar observations. Extremely high visibility was recognized.

On this day, the main wind direction is west so that BERTHA (pointing to the west, zenith angle of $45^{\circ}$ ) detects the top parts of the plumes first. Consequently, the columns are tilted to the left in the colour plots. Horizontal winds are weak in the lowest $500 \mathrm{~m}$ and moderate with $4-8 \mathrm{~m} \mathrm{~s}^{-1}$ in the upper part of the aerosol layer, and strong at greater heights. Wind direction is not constant in the lowest $500 \mathrm{~m}$. Wind shear with height probably causes mechanically generated turbulence that may have favoured strong convection of the hot dust plumes on this day. Note the wiggles in the profile of the virtual potential temperature which indicate strong vertical mixing.

The dust-layer optical depth is only 0.025 at $500 \mathrm{~nm}$ during the lidar measurement period. Unfortunately, an optically thin glaciated mid-altitude cloud and a cirrus layer covered the field site most of the time, so that trustworthy Ångström exponents for the dust layer are not available. However, even with these clouds the overall particle optical depth did not exceed 0.05 during the day. Vigorous convection pattern as on May 23 are also observed on May 29 and 30, on two other days with low optical depth.

\subsection{Plume statistics for five days}

We counted the plume clusters and isolated plumes in Figs. 2 and 5, and carefully inspected the depolarization-ratio heighttime displays regarding the top height of the convective features. The results are presented in Table 1. TNP is the total number of plumes that are detected within the lidar observational period (second column of Table 1). TNP values for May 16 and 23 as well as for May 14, 17 and 18 are presented. On all of these $5 \mathrm{~d}$ appropriate wind conditions (westerly winds or easterly winds) prevailed so that the chance was largest to detect the full vertical extend of most of the convective plumes above about $300 \mathrm{~m}$ height. As mentioned above, the lidar beam was pointed to the west and the beam zenith angle was $30^{\circ}-45^{\circ}$ in most observations. In the case of southerly winds, when the air flow is orthogonal to the laser beam, only a short segment of any plume can be detected. At such conditions a statistics on plume top heights is not possible.

5-11 plumes and plume clusters per hour were observed on the convectively active days May 14-18. The frequency of occurrence $F O P$, also denoted as activity index in the literature, reaches a value of 26 plumes per hour on May 23. The frequency distribution of the top heights indicates that most of the plumes (50-95\%) are less than one kilometre on May 16-18, and 23 and thus within the lower dust layer (0.3DHL). On May 14 and $16,18-25 \%$ of the plume tops reach heights $>1.5 \mathrm{~km}$ above the lidar, no plume tops $>1.5 \mathrm{~km}$ are found on May 17, and only $5-8 \%$ of the plumes show top heights $>1.5 \mathrm{~km}$ on May 18 and 23.

In Table 1, plumes with top heights $<300 \mathrm{~m}$ are not considered (not detected with lidar). We suggest that almost all columns that are larger than $500 \mathrm{~m}$ are convective plumes, whereas a considerable part of the columns with heights of 300-500 m may be dust devils. More than $50 \%$ of the plumes were smaller than $500 \mathrm{~m}$ in height on May 23 (Fig. 5).

The maximum top height observed on May 14, 16 and 18 is 2000-2200 m, $1100 \mathrm{~m}$ on 17 May, and close to $3000 \mathrm{~m}$ on 23 May, or 0.57DLH (May 14), 0.5DLH (May 16), 0.31DLH (May 17) and 0.69DLH (May 18) with the dust layer height DLH in Table 1. No background dust layer was found on May 23.

Bell (1969) reported eight cases with tall plumes. He found the maximum top height of plume ensembles from 1200 to $2400 \mathrm{~m}$ (average was $1725 \mathrm{~m}$ ). Hess and Spillane (1990) analysed 18 cases of observed plume distributions. In 8 out of the 18 cases $(45 \%)$ the maximum top height was $<300 \mathrm{~m}, 4(22 \%)$ and 5 cases $(28 \%)$ are reported with maximum top height from 300 to $1000 \mathrm{~m}$ and from 1000 to $2000 \mathrm{~m}$, respectively. Only one case $(5 \%)$ was found with maximum top height exceeding the $2000 \mathrm{~m}$ value.

Table 1 also provides estimates of the number of plumes and plume clusters that were, on average, observable in $1 \mathrm{~km}^{2}$ 
during the respective lidar observational period. The values for $\mathrm{P} \mathrm{km}^{-2}$ are calculated in the following way. On May 16, for example, we observed 5.3 plumes per hour or, on average, one plume every $680 \mathrm{~s}$ (11.3 min). If we assume a mean horizontal wind speed of roughly $5 \mathrm{~m} \mathrm{~s}^{-1}$ (according to the radiosonde observation around $1000 \mathrm{~m}$ height above the lidar), individual plumes and plume clusters were separated on average by about $3400 \mathrm{~m}$. Thus, on average, about 0.3 plumes per kilometre were observed. If we now further assume that the lidar detects any plume of $100-400 \mathrm{~m}$ diameter in a radius of $150 \mathrm{~m}$ around the laser beam (300-m detection corridor) so that we observed 0.3 plumes per $0.3 \mathrm{~km}^{2}$ we may estimate that about 1 plume per $\mathrm{km}^{2}$ was present at any time during the lidar observational period on May 16. In the same way the values of $\mathrm{P} \mathrm{km}^{-2}$ for the other days were computed. The needed wind information was taken from radiosonde ascents. According to Table 1, we found values ranging from 1 to 8 plume-like features per kilometre square.

Hess and Spillane (1990) report a mean value of 30-35 plumes within a field of view of $90 \mathrm{~km}^{-2}$ or a mean value of $\mathrm{P} \mathrm{km}-2$ of $0.33 \mathrm{~km}^{-2}$. Similar average numbers were found by Bell (1969). He reports that in most cases $20-40$ plumes within an area of roughly $90 \mathrm{~km}^{2}$ were observed. In one case several hundreds of convective plumes were observed at one time over western Queensland in Australia, and thus certainly more than 2 plumes per $\mathrm{km}^{2}$.

We use the field study of Carroll and Ryan (1970) to check how reasonable our comparably high FOP (and corresponding $\mathrm{P} \mathrm{km}^{-2}$ ) values are. The sample area selected by Carroll and Ryan (1970) is of similar size as the area seen by the lidar within $1 \mathrm{~min}$ (200-500 $\mathrm{m}$ in length for mean horizontal velocity of 3$7 \mathrm{~m} \mathrm{~s}^{-1}$ ). It should be mentioned, that by-eye observations tend to underestimate plume occurrence with increasing observation area. Balme and Greeley (2006) summarize available dust devil census studies. The number of reported mean plume occurrence frequency steadily decreases for reported field sites of $0.15,33$, $65,90,388$ and $500 \mathrm{~km}^{-2}$.

The $300 \times 500 \mathrm{~m}\left(0.15 \mathrm{~km}^{-2}\right)$ field site of Carroll and Ryan (1970) was situated in the Mojave Desert in southern California. They counted 26-222 plumes per day (within observation periods from 2.5 to $5.8 \mathrm{~h}$ ) on $10 \mathrm{~d}$ from April to September 1969. Plume occurrence frequencies of 0.34 $0.83 \mathrm{~min}^{-1}$ or $20-50$ plumes per hour are reported for most of the cases in the summer months. Our lidar-derived FOPs of 5-26 plumes per hour agree well with these values, keeping in mind that we counted each plume cluster as one event. A cluster may have formed from several single plumes.

\section{Surface and air temperature observations}

The formation of dust devils and convective plumes is mainly controlled by the vertical temperature distribution in the lowest few metres of the atmosphere (Ryan, 1972; Oke et al., 2007a).
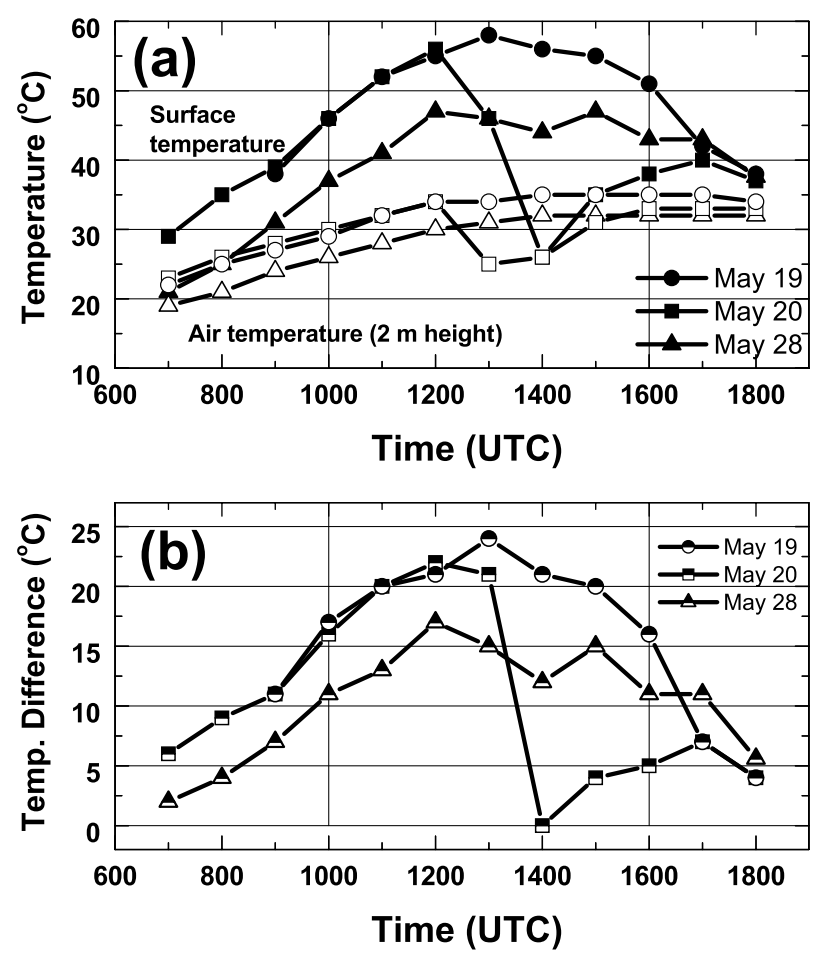

Fig. 6. Temporal development of (a) surface temperature (solid symbol), and air temperature (open symbol, $2 \mathrm{~m}$ height), and (b) respective difference of surface to air temperature (half-filled symbol) on May 19, 20 and 28, $2006($ UTC = LT). Measurements are taken at Ouarzazate Airport.

High superadiabatic temperature gradients caused by soil surface temperatures of up to about $60^{\circ} \mathrm{C}$ is a prerequisite for strong convective motions. In this section we discuss the surface, 1 - and 2-m air temperatures observed at Ouarzazate and Trab Labied during days with convective plume activity.

Figure 6a illustrates the diurnal development of the surface temperature and the air temperature at $2 \mathrm{~m}$ height observed at Ouarzazate for $2 \mathrm{~d}$ with convective plume development (May 19, 20) and $1 \mathrm{~d}$ (May 28) on which plumes were not detected. As mentioned above, unfortunately observations of the surface temperature are not available for the period May 16-18. In addition, for May 23, surface temperatures are available only for the short time period from 1220 to 1440 UTC and thus not for the period of the lidar observation.

The surface temperature in Fig. 6a shows a strong increase in the morning on the order of $5^{\circ} \mathrm{C}$ per hour and a maximum around 1300 UTC on a clear day (May 19). The air temperature increases less quickly during the morning, but remains at a high level until the early evening. As a consequence the surface-to-air temperature difference shows a pronounced diurnal cycle with a maximum close to 1300 UTC (Fig. 6b). Because of a rain shower between 1230 and 1330 UTC on May 20, the surface temperature strongly decreased in the early afternoon and recovered slowly until 1800 UTC. 
The comparison of the air and surface temperatures at Trab Labied with Ouarzazate for May 19 indicates that the temperatures were similar at the two sites taking the differences in the elevation of $1130 \mathrm{~m}$ (Ouarzazate) and $1380 \mathrm{~m}$ (Trab Labied) into account. Weather maps and satellite pictures suggest that the conditions were also similar for May 16. On May 23, horizontally inhomogeneous altocumulus and cirrus cloud fields were present over Ouarzazate area, so that the Trab Labied data cannot be used to describe the temperature conditions in the lowest metres of the atmosphere at Ouarzazate on this day.

According to the observations at Trab Labied the maximum surface temperature was probably close to $55^{\circ} \mathrm{C}$ at Ouarzazate on May 16 and thus slightly lower than on May 19. The difference between surface temperature and air temperature at $2 \mathrm{~m}$ height reaches maximum values of $22-23^{\circ} \mathrm{C}$ around noon on all days from May 16 to 19 at Trab Labied, as shown for Ouarzazate on May 19 in Fig. 6b. As often reported in the literature (Balme and Greeley, 2006), dust devil activity is restricted to the time period from about 1000 to 1600 LT (indicated by vertical lines in Figs. 6a and b). Obviously the difference between surface temperature and 2-m air temperature must exceed a value of 17$20 \mathrm{~K}$ before convective plumes can develop. Such favourable conditions were not given on May 28. Column-like structures were not detected with lidar on May 28. The main reason is the high soil moisture and decreased Bowen ratio after the strong thunderstorm on May 27.

As pointed out by Ryan (1972), the temperature lapse rate in the highly superadiabatic layer from roughly $0.3 \mathrm{~m}$ to $10 \mathrm{~m}$ above the surface is the basic determinant for the dust devil occurrence frequency. In almost $90 \%$ of the observations of Ryan and Carroll (1970) the temperature lapse rate in the surface layer from 0.3 to $10 \mathrm{~m}$ was between 0.15 and $0.4^{\circ} \mathrm{C} \mathrm{m}^{-1}$ during the late morning and early afternoon hours when dust devils occur. This range of lapse rates is indicated in Fig. 7 which provides information on the vertical temperature profile in the lowest $10 \mathrm{~m}$ over the surface at Ouarzazate. In addition, the resulting temperature gradients in the lowermost $30 \mathrm{~cm}$ above the ground are given in Fig. 7. The Ryan-1972 model (two layers from 0 to 30 and $30 \mathrm{~cm}$ to $10 \mathrm{~m}$ height) is adjusted to the surface temperature measured with the spectrometer and the $10 \mathrm{~m}$ temperature observed with radiosonde in Fig. 7. Both temperatures are taken at 1038 UTC.

Ryan (1972) observed temperature lapse rates from 60 to $100^{\circ} \mathrm{C} \mathrm{m}^{-1}$ in the lowest $30 \mathrm{~cm}$ during the occurrence of dust devils in the Mojave Desert in south California. As can be seen, a temperature lapse rate of more than $50^{\circ} \mathrm{C} \mathrm{m}^{-1}$ in the lowest $30 \mathrm{~cm}$ is shown in Fig. 7 for Ouarzazate.

Oke et al. (2007a) reported that temperature lapse rates of $>0.9^{\circ} \mathrm{C} \mathrm{m}^{-1}$ are required from 12 to $252 \mathrm{~cm}$ before first dust devils (or Willy-willies) appear. The temperature conditions after Oke et al. (2007a) are consistent with the Ryan-1972 model when the strong decrease of the temperature occurs in the lowest $10 \mathrm{~cm}$ above the ground, followed by a temperature gradient around $1^{\circ} \mathrm{C} \mathrm{m}^{-1}$ up to $2.5 \mathrm{~m}$ height, and a correspondingly low

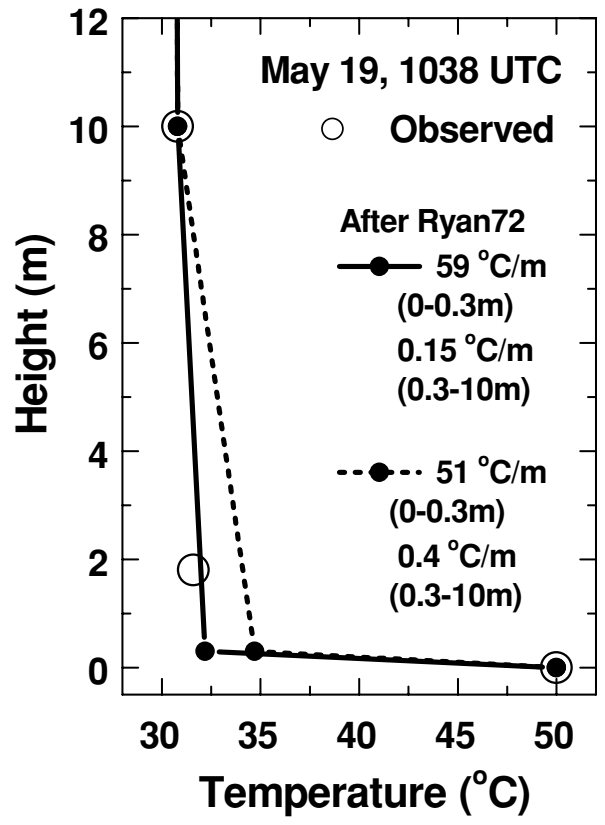

Fig. 7. Surface temperature and air temperatures measured with infrared spectrometer and radiosonde (big open circles) at Ouarzazate, and temperature gradients after Ryan (1972). The Ryan model profile (with two layers from 0 to $0.3 \mathrm{~m}$ and 0.3 to $10 \mathrm{~m}$ ) was constrained to the temperatures measured at 0 and $10 \mathrm{~m}$ height. Two different temperature gradients $(0.3-10 \mathrm{~m})$ are assumed. They are indicated by solid and dashed profiles. The resulting temperature gradients for the layers from 0 to 0.3 height are given as numbers.

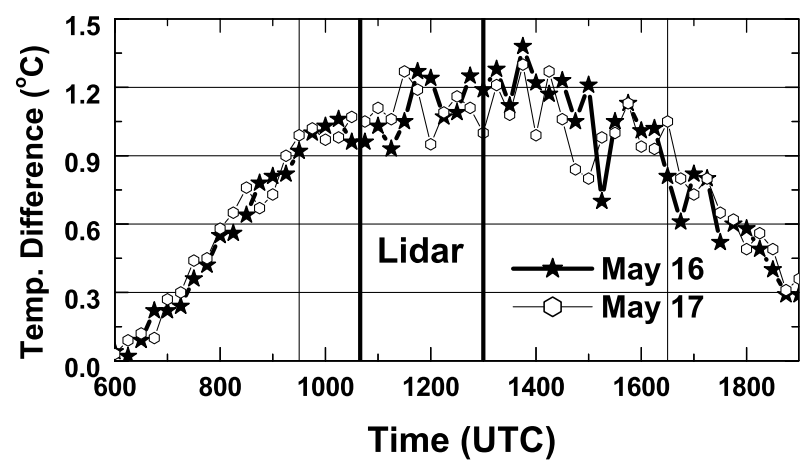

Fig. 8. Difference between the 1- and 2-m air temperatures measured at Trab Labied. Data are given with a resolution of $15 \mathrm{~min}$. Thin vertical lines mark the time interval from 0930 to 1630 UTC during which the temperature difference is mostly above $0.9^{\circ} \mathrm{C}$, thick solid lines indicate the lidar observational period from 1040 to 1256 UTC on May 16 (Fig. 2).

temperature lapse rate of $0.05-0.1^{\circ} \mathrm{C} \mathrm{m}^{-1}$ from 2.5 to $10 \mathrm{~m}$ height.

Figure 8 shows the temperature gradient observed at Trab Labied between 1 and $2 \mathrm{~m}$ above ground on May 16 and 17 . The temperature lapse rate exceeds $0.9^{\circ} \mathrm{C} \mathrm{m}^{-1}$ from 930 to 1630 UTC with few exceptions. The variability of the temperature 


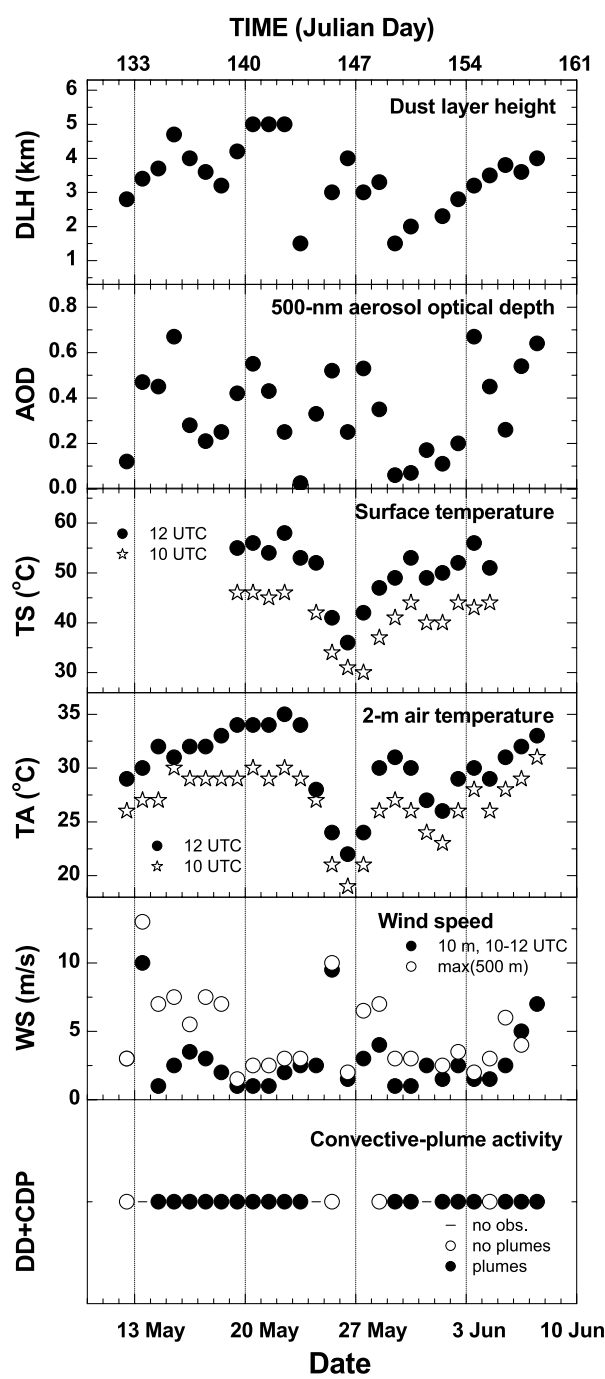

Fig. 9. Overview of SAMUM environmental and meteorological conditions and convective plume activity during the late morning hours (10-12 UTC). Time series of the dust layer height (DLH from lidar), 500-nm particle optical depth (AOD from AERONET photometer), surface temperature (TS), air temperature (TA, $2 \mathrm{~m}$ height), wind speed (WS, $10 \mathrm{~m}$ height, 10-12 UTC mean, and maximum wind speed in the lowest $500 \mathrm{~m}$ of the atmosphere as observed with radiosonde), and convective plume activity (DD+CDP) are shown. No lidar observation was performed on days with minus sign, an open circle denotes that no dust plume was detected, and a filled circle stands for a day with dust plumes detected.

difference in Fig. 8 is significantly higher after 1100 UTC than before 1100 UTC. This behaviour is probably the result of strong convective mixing by dust devils and dust plumes that crossed the meteorological station. Strong convective plumes were not observed with lidar before 1100 UTC on May 16 and before 1015 UTC on May 17.

Figure 9 finally provides an overview of the meteorological and environmental (dust) conditions during SAMUM. Shown are dust layer height, particle optical depth at $500 \mathrm{~nm}$, surface temperature at 1000 and 1200 UTC, 2-m air temperature at 1000 and 1200 UTC, 10-m wind speed (meteorological station, 10-12 UTC mean) and the maximum wind speed in the lowest $500 \mathrm{~m}$ above ground from radiosonde. It is interesting to note that none of the previous dust-devil observational studies reported in the literature provided information on the particle optical depth of the boundary layer aerosol. The dust load reflects and attenuates sunlight and thus influences surface heating. Low dust optical depths $(<0.3)$ seem to favour dust plume formation.

The bottom panel in Fig. 9 indicates the days without dust devils and plumes and days with few to many convective plumes. It should be mentioned that days even with only one dust plume (as indicated by lidar) were counted as dust devil days and that the census is exclusively based on the lidar observational periods. That means a day was counted as no-plume day if no dust plume was observed during the lidar session, even if a lot of dust plumes would have been observable afterwards.

After the period with strong Saharan dust advection to Ouarzazate from May 13 to 22 (see also Knippertz et al., 2008), during the second phase from May 23 to June 2 variable dust conditions with sometimes exceptionally clear air indicated by a particle optical depth as low as 0.025-0.07 (May 23, 29 and 30) dominated. Partly strong thunderstorms and rainfall (more then $10 \mathrm{~mm}$ rain in $1 \mathrm{~h}$ on May 27) occurred from May 24 to 27 . The 2-m air temperature was below $25^{\circ} \mathrm{C}$ on May 25-27. The slowly recovering surface temperatures in Fig. 9 suggest that about $2 \mathrm{~d}$ (May 28 and 29) were needed to evaporate the soil moisture. The third phase (after June 3) was again dominated by a strong air flow from the Sahara.

Wind speed was generally low with few exceptions. According to Hess and Spillane (1990), wind velocities near the surface must be below a critical value to allow plume formation. At high wind speeds mechanical turbulent mixing seems to prevent the growth of the necessary patterns of convection. Oke et al. (2007a) recently confirmed that willy-willies occur only when the horizontal wind velocity (measured at $252 \mathrm{~cm}$ height) is in the range of $1.5-7.5 \mathrm{~m} \mathrm{~s}^{-1}$. Our observations corroborate that. Many plumes were detected on days with wind speeds from 2 to $7 \mathrm{~m} \mathrm{~s}^{-1}$ (May 16-18, and 23 and June 2 and 7). No plume was observed on May 25, a day with high wind speed. Plumes did probably also not develop on May 13 (at wind speeds of $>10 \mathrm{~m} \mathrm{~s}^{-1}$ ).

\section{Summary}

Detailed observations of vertical profiles of convective plumes were presented for the first time. The lidar observations were mainly based on depolarization measurements. A dense set of meteorological data were available to describe the conditions at which dust devils and convective plumes developed at Ouarzazate in southern Morocco.

Two case studies with typical and vigorous formation of dust devils, convective plumes and thermals were presented. For 
five SAMUM days detailed statistics on plume occurrence frequency and plume top heights have been provided. The results were found to be in good agreement with measurements in the literature.

The majority of convective plumes showed top heights of $<1 \mathrm{~km}$ or $0.3 \mathrm{DLH}$ with the Saharan dust layer height DLH of typically 3-4 km. On $1 \mathrm{~d}$, all plumes were lower than $1.5 \mathrm{~km}$ height a.g.1. 5-25\% of the plumes reached heights of $1.5-3.0 \mathrm{~km}$ on the other $4 \mathrm{~d}$. The maximum values of the plume top height ranged from 1.1 to $2.9 \mathrm{~km}$ on the $5 \mathrm{~d}$. The plumes occurred with a frequencies of 5-26 plumes and plume clusters per hour. Observed height-to-diameter ratio was on the order of 2-10.

From the measured ground, surface, and air temperatures we concluded that a difference of surface to 2-m air temperature of $17-20 \mathrm{~K}$ is required before convective plumes develop. We confirmed that the difference between the 1 and 2-m air temperature must exceed a threshold value of $0.9-1{ }^{\circ} \mathrm{C}$ before plumes form. Favourable horizontal wind speeds are 2-7 $\mathrm{m} \mathrm{s}^{-1}$. A low dust optical depth $(<0.3)$ seems to be of advantage for plume evolution.

More lidar observations (preferably with continuously running systems) of the three-dimensional structure of plumes and devils in a variety of arid and semi-arid regions around the globe are required. Our snapshot-like observations can be regarded as a first feasibility study. The combined use of an aerosol lidar and wind Doppler lidar as described by Engelmann et al. (2008) may be an appropriate attempt to quantify the aerosol flux in dust plumes and to investigate, in this way, the role of dust devils in the climate system.

\section{Acknowledgments}

The SAMUM research group is funded by the Deutsche Forschungsgemeinschaft (DFG) under grant number FOR 539. We thank the AERONET team for instrument calibration and for data analysis. We furthermore thank the Johannes Gutenberg University Mainz for its financial support through the research funds of the University of Mainz. The IMPETUS project is supported by the Federal German Ministry of Education and Research (BMBF) under grant No. 01 LW 06001B and by the Ministry of Innovation, Science, Research and Technology (MIWFT) of the federal state of Northrhine-Westfalia under grant No. 313-21200200.

\section{References}

Alfaro, S. C., Gaudichet, A., Gomes, L. and Maillé, M. 1997. Modeling the size distribution of a soil aerosol produced by sandblasting. $J$. Geophys. Res. 102, 11 239-11249.

Althausen, D., Müller, D., Ansmann, A., Wandinger, U., Hube, H. and co-authors. 2000. Scanning 6-wavelength 11-channel aerosol lidar. J. Atmos Oceanic Technol. 17, 1469-1482.

Ångström, A. 1961. Techniques for determining the turbidity of the atmosphere. Tellus 13, 214-223.
Ansmann, A., Bösenberg, J., Chaikovsky, A., Comerón, A., Eckhardt, S. and co-authors. 2003. Long-range transport of Saharan dust to northern Europe: the 11-16 October 2001 outbreak observed with EARLINET. J. Geophys. Res. 108, doi:10.1029/2003JD003537.

Ansmann, A., Tesche, M., Althausen, D., Müller, D., Freudenthaler, V. and co-authors. 2008. Influence of Saharan dust on cloud glaciation in southern Morocco during SAMUM. J. Geophys. Res. 113, doi:10.1029/2007JD008785.

Balme, M. and Greeley, R. 2006. Dust devils on Earth and Mars. Geophys. Rev. 44, 1-22.

Bell, F. 1969. Dust devils and aviation. Meteor. Note No 27, Australia, Bureau of Meteor., 9 pp. 272-276.

Bluestein, H. B., Weiss, C. C. and Pazmany, A. L. 2004. Doppler radar observations of dust devils in Texas. Mon. Wea. Rev. 132, 209-224.

Carroll, J. J. and Ryan, J. A. 1970. Dust devil wind velocities: mature state. J. Geophys. Res. 75, 5179-5184.

Engelmann, R., Wandinger, U., Ansmann, A., Müller, D., Zeromskis, E. and co-authors. 2008. Lidar observations of the vertical aerosol flux in the planetary boundary layer. J. Atmos. Oceanic Techn. 25, 1296-1306.

Engelstaedter, S. and Washington, R. 2007. Temporal controls on global dust emissions: the role of the surface gustiness. Geophys. Res. Lett. 34, doi:10.1029/2007GLD029971.

Freudenthaler, V., Esselborn, M., Wiegner, M., Heese, B., Tesche, M. and co-authors. 2008. Depolarization-ratio profiling at several wavelengths in pure Saharan dust during SAMUM 2006. Tellus 61B, doi:10.1111/j.1600-0889.2008.00396.x.

Gillette, D. A. and Sinclair, P. C. 1990. Estimation of suspension of alkaline material by dust devils in the United States. Atmos. Environ. 24, 1135-1142.

Greeley, R., Balme, M. R., Iversen, J. D., Metzger, S., Mickelson, R. and co-authors. 2003. Martian dust devils: laboratory simulations of particle threshold. J. Geophys. Res. 108, doi:10.1029/2002JE001987.

Heintzenberg, J. 2008. The SAMUM-1 experiment over Southern Morocco: overview and introduction. Tellus 61B, doi:10.1111/j.16000889.2008.00403.x.

Hess, G. D., Spillane K. T. and Lourensz, R. S. 1988. Atmospheric vortices in shallow convection. J. Appl. Meteorol. 27, 305-317.

Hess, G. D. and Spillane, K. T. 1990. Characteristics of dust devils in Australia. J. Appl. Meteorol. 29, 498-507.

Holben, B. N., Eck, T. F., Slutsker, I., Tanré, D., Buis, J. P. and co-authors. 1998. AERONET - A federated instrument network and data archive for aerosol characterization. Remote Sens. Environ. 66, 1-16.

Hunt, J. C. R., Kaimal J. C. and Gaynor, J. E. 1988. Eddy structure in the convective boundary layer-new measurements and new concepts $Q$. J. R. Meteorol. Soc. 114, 827-858.

Kahn, R. A., Petzold, A., Wendisch, M., Bierwirth, E., Dinter, T. and coauthors. 2008. Desert dust aerosol air mass mapping in the western Sahara, using particle properties derived from space-based multiangle imaging. Tellus 61B, doi:10.1111/j.1600-0889.2008.00398.x.

Kaimal, J. C. and Businger, J. A. 1970. Case studies of a convective plume and a dust devil. J. Appl. Meteorol. 9, 612-620.

Knippertz, P., Deutscher, C, Kandler, K., Müller, T., Schulz, O. and coauthors. 2007. Dust mobilization due to density currents in the Altlas region: observations from the Saharan Mineral Dust Experiment 2006 field campaign. J. Geophys. Res. 112, doi:10.1029/2007JD008774.

Knippertz, P., Ansmann, A., Althausen, D., Müller, D., Tesche, M. and co-authors. 2008. Dust mobilization and transport in the northern 
Sahara during SAMUM 2006-a meteorological overview. Tellus 61B, doi:10.1111/j.1600-0889.2008.00380.x.

Koch, J. and Renno, N. O. 2005. The role of convective plumes and vortices on the global aerosol budget. Geophys. Res. Lett. 32, doi:10.1029/2005GL023420.

Marticorena, B. and Bergametti, G. 1995. Modeling the atmospheric dust cycle: 1. Design of a soil-derived dust emission scheme. J. Geophys. Res. 100, 16415-16430.

Mattsson, J. O., Nihlén, T. and Yue, W. 1993. Observations of dust devils in a semi-arid district of southern Tunisia. Weather 48, 359363.

Monteith, J. L. 1973. Principles of Environmental Physics. Chapter 8. Edward Arnold, New York .

Oke, A. M. C., Trapper, N. J. and Dunkerley, D. 2007a. Willy-willies in the Australian landscape: the role of key meteorlogical variables and surface conditions in defining frequency and spatial characteristics. $J$. Arid Environ. 71, 201-215.

Oke, A. M. C., Dunkerley, D. and Trapper, N. J. 2007b. Willy-willies in the Australian landscape: sediment transport characteristics. J. Arid Environ. 71, 216-228.

Renno, N. O. and Ingersoll, A. P. 1996. Natural convection as a heat engine: a theory for CAPE. J. Atmos. Sci. 53, 572-585.

Renno, N. O., Abreu, V. J., Koch, J., Smith, P. H., Hartogensis, O. K. and co-authors. 2004. MATADOR 2002: a pilot field experiment in convective plumes and dust devils. J. Geophys. Res. 109, doi:10.1029/2003JE002219.

Ryan, J. A. 1972. Relation of dust devil frequency and diameter to atmospheric temperature. J. Geophys. Res. 77, 7133-7137.

Ryan, J. A. and Carroll, J. J. 1970. Dust devil wind velocities: mature state. J. Geophys. Res. 75, 531-541.
Schulz, O. 2006. Analyse schneehydrologischer Prozesse und Schneekartierung im Einzugsgebiet des Oued M'Goun, Zentraler Hoher Atlas (Marokko). PhD thesis, University of Bonn, Germany

Shao, Y. 2001. A model for mineral dust emission. J. Geophys. Res. 106, 20 239-20254.

Sinclair, P. C. 1964. Some preliminary dust devil measurements. Mon. Wea. Rev. 92, 363-367.

Sinclair, P. C. 1969. General characteristics of dust devils. J. Appl. Meteorol. 8, 32-38.

Sinclair, P. C. 1973. The lower structure of dust devils. J. Atm. Science 30, 1599-1619.

Snow, J. T. and McClelland, T. M. 1990. Dust devils at White Sands Missile Range, New Mexico, 1. temporal and spatial distributions. $J$. Geophys. Res. 95, 13707-13 721.

Speth, P. and Diekkrüger, B. 2006. An integrated approach to the efficient management of scarce water resources in West Africa - case studies for selected river catchments in different climatic zones. Second Final Report, Institute of Geophysics and Meteorology, University of Cologne, Kerpener Str. 13, 50923 Köln, Germany .

Stull, R. B. 1988. An Introduction to Boundary Layer Meteorology. Kluwer Academic Publishers, Dordrecht/Boston/London , 274276.

Tesche, M., Ansmann, A., Müller, D., Althausen, D., Mattis, I. and coauthors. 2008. Vertical profiling of Saharan dust with Raman lidars and airborne HSRL in southern Morocco during SAMUM. Tellus 61B, doi:10.1111/j.1600-0889.2008.00390.x.

van As, D., van den Broeke, M. R. and Helsen, M. M. 2006. Structure and dynamics of the summertime atmospheric boundary layer over the Antarctic Plateau: 1. Measurements and model validation. J. Geophys. Res. 111, doi:10.1029/2005JD005948. 